\title{
Bacterial death induced by expression of the intracellular portion of human Fas
}

\author{
Yili Yang ${ }^{1}$, June S. Hong ${ }^{1}$, Astrid Eder ${ }^{1}$ and \\ Jonathan D. Ashwell*,1 \\ 1 Laboratory of Immune Cell Biology, Division of Basic Sciences, National \\ Cancer Institute, National Institutes of Health, Bethesda, Maryland, MD 20892, \\ USA \\ * corresponding author: J.D. Ashwell, Building 10, Room 1B-40, National \\ Institutes of Health, Bethesda, MD 20892, USA. tel: 301-496-4931; \\ e-mail: jda@box-j.nih.gov
}

Received 22.3.99; revised 7.6.99; accepted 21.6.99

Edited by B. Osborne

\begin{abstract}
In attempting to produce the intracellular portion of human Fas $\left(\mathrm{IC}_{175-319}\right)$ as a GST-fusion protein we found that expression of GST-IC $175-319$, but not GST alone or GST-IC $231-298$ (containing the Fas death domain), rapidly caused the death of host $E$. coli cells. Expression of GST-IC ${ }_{175-319}$ with a single amino acid substitution (V238N) corresponding to the mouse $\mathrm{Ipr}^{\mathrm{cg}}$ mutation, or E245A, which abolishes the ability of Fas to self-associate, did not kill bacteria. Deletional analysis identified a 20 -amino acids region $\left(\mathrm{Asp}_{210}-\right.$ Lys $\left._{230}\right)$ as essential for the killing activity, and introduction of a single amino acid substitution (T225P) in this 20 amino acid region markedly decreased the ability of Fas- $I_{175-319}$ to cause bacterial death. These data indicate that Fas can deliver a death signal in prokaryotic organisms by a means that shares some features with eukaryotic cells, and raise the possibility that certain mechanisms leading to programmed cell death may be conserved from bacteria to mammalian cells.
\end{abstract}

Keywords: Fas; CD95; bacteria; programmed cell death

Abbreviations: Fas-IC, intracellular portion of Fas; GST, glutathione S-transferase; IPTG, isopropyl- $\beta$-D-thiogalactoside

\section{Introduction}

Fas (CD95) is a type I transmembrane protein that belongs to the TNF/NGF receptor superfamily. ${ }^{1,2}$ Engagement of Fas with anti-Fas antibody or Fas ligand results in apoptotic cell death. ${ }^{3-5}$ Fas-mediated apoptosis is essential for lymphocyte homeostasis, contributes to killing by cytotoxic T cells and NK cells, and is required for the maintenance of immune privilege in certain tissues. ${ }^{6-8}$ Comparison of the amino acid sequence of Fas and the type 1 TNF receptor (p55) revealed a conserved region of approximately 68 amino acids, corresponding to human Fas 231-298, that is required for induction of apoptosis by both receptors, and hence was termed the 'death domain'. 9,10 Subsequent studies have shown that the death domain of Fas binds with another death domaincontaining protein (MORT1 or FADD) whose $\mathrm{N}$-terminus in turn interacts with caspase-8 (also known as FLICE or $\mathrm{MACH}) .{ }^{11,12}$ The formation of this complex activates caspase- 8 and initiates the intracellular cascade that results in apoptosis. ${ }^{13-15}$ It appears that the aggregation of caspase8 is sufficient for this purpose, since heterologous oligomerization of caspase-8 is sufficient to activate its activity and trigger apoptosis. ${ }^{16,17}$

Simply expressing Fas does not necessarily confer susceptibility to Fas-mediated death. For example, human peripheral blood $\mathrm{T}$ lymphocytes express high levels of Fas within $24 \mathrm{~h}$ of activation, yet are resistant to killing by antiFas antibodies, although FADD and caspase-8 seem to be constitutively expressed. ${ }^{11,12,18}$ Fas-mediated signaling also requires tyrosine phosphatase SHP-1 and can be regulated by agonists for PKA and PKC. ${ }^{19,20}$ It is not clear how these molecules interact with the Fas/FADD/caspase-8 axis. Furthermore, Fas interacts with a number of other proteins, such as RIP, FAF-1, FAP-1, and Daxx, ${ }^{21-24}$ raising the possibility that molecules other than FADD may be involved in proximal transduction of Fas-mediated signals. Indeed, it has been shown that Daxx enhances Fas-mediated apoptosis and appears to transduce Fasmediated death signals by activating JNK and caspases. ${ }^{24}$

As part of a study to identify molecules that interact with Fas, we attempted to produce a recombinant protein consisting of the intracellular portion of Fas $\left(I_{175-319}\right)$ fused to GST. Unexpectedly, expression of the intracellular portion of Fas caused death of host bacteria. Since it has been shown that, like mammalian cells and single cell eukaryotic organisms, bacteria can undergo programmed cell death under certain circumstances, ${ }^{25}$ this prompted us to characterize the molecular requirements for this inducible form of bacterial cell death.

\section{Results}

\section{Induction of Fas-IC $175-319$ in E. coli causes death of the bacteria}

The E. coli strain $\mathrm{DH} 5 \alpha$ was transformed with the plasmids pGEX-2T (encoding GST alone), pGEX-IC $175-319$ (containing the entire intracellular portion of Fas), or pGEX-IC $231-298$ (containing the classic Fas death domain) (Figure 1). A single colony of each plasmid-containing bacterium was inoculated into Super Broth medium and treated with IPTG to induce protein expression by the transforming plasmid. After incubation with glutathione Sepharose 4B, the precipitated proteins were separated by SDS-PAGE and stained with Coomassie Blue. While the expression of GST and GST$\mathrm{IC}_{231-298}$ were greatly induced by IPTG, reproducibly very low levels of GST-IC $175-319$ were detected (data not shown). 
Because overexpression of Fas has been shown to induce eukaryotic cell death in the absence of ligand, ${ }^{16,17}$ we considered the possibility that the GST-Fas-IC fusion protein was causing the death of these prokaryotic cells. To determine if expression of GST-IC $_{175-319}$ was killing the bacteria, viable cells in the culture were counted using a spread-plate method. As shown in Figure 2A, IPTG had no effect on the number of colonies from bacteria containing pGEX-2T or pGEX-IC $231-298$ (pGEX-2T: $2.3 \times 10^{9}$ c.f.u. $/ \mathrm{ml}$ in medium alone, $2.0 \times 10^{9}$ c.f.u./ml after treatment with IPTG; pGEX-IC $231-298: 2.7 \times 10^{9}$ c.f.u. $/ \mathrm{ml}$ in medium alone, $2.9 \times 10^{9}$ c.f.u./ml after treatment with IPTG). In contrast, the number of $\mathrm{pGEX}-\mathrm{IC}_{175-319}$-containing bacteria was reduced approximately 2000 -fold by treatment with IPTG (from $2.3 \times 10^{9}$ c.f.u. $/ \mathrm{ml}$ to $1.0 \times 10^{6}$ c.f.u. $/ \mathrm{ml}$ ). The decrease of viable bacteria was dependent on the concentration of IPTG, with an $\mathrm{ED}_{50}$ of approximately $10 \mu \mathrm{M}$ (Figure $2 \mathrm{~B}$ ).
To directly determine whether the bacterial cells expressing cells were being killed by IPTG induction of GST-IC $175-319$ synthesis, use was made of the fluorescent vital dye rhodamine $123 . .^{26,27}$ This watersoluble cationic dye is highly concentrated by mitochondria in an energy-dependent manner ${ }^{28}$ and has been used to directly assess the viability of bacteria. ${ }^{27}$ As shown in Figure 3, EDTA-permeabilized bacteria took up rhodamine 123 (compare Figure $3 A, B$ and $C$ with $D, E$ and $F$ respectively). The staining profiles of pGEX-2Tand $\mathrm{pGEX}-\mathrm{IC}_{231-298}$-containing bacterial showed little change in the presence of IPTG (compare Figure 3D with $\mathrm{G} ; \mathrm{F}$ with I). In contrast, the mean fluorescence of pGEX-IC ${ }_{175-319}$-containing bacteria decreased in the presence of IPTG (compare Figure $3 \mathrm{E}$ and $\mathrm{H}$ ), yielding a profile that was similar to unstained bacteria (compare Figure $3 \mathrm{~B}$ and $\mathrm{H}$ ). Thus, induction of Fas- $\mathrm{IC}_{175-319}$
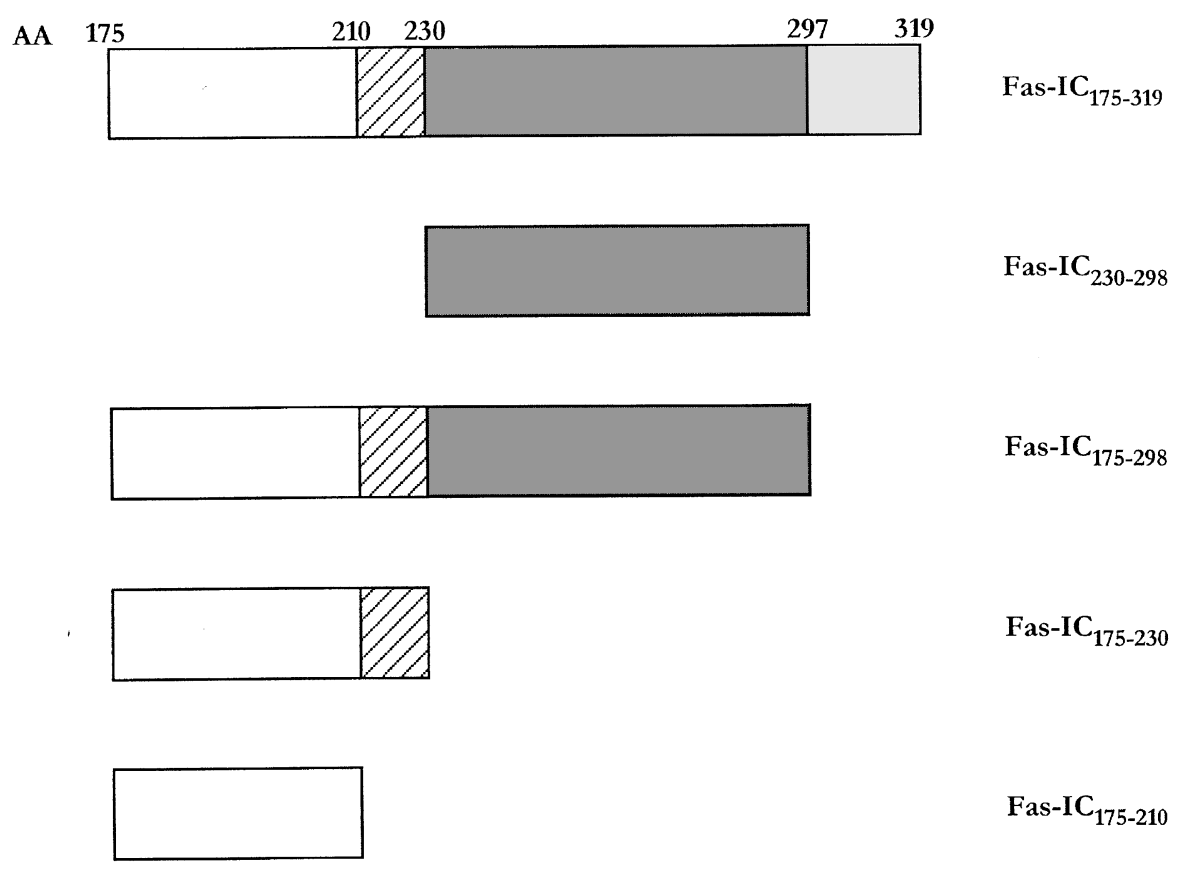

Fas-IC

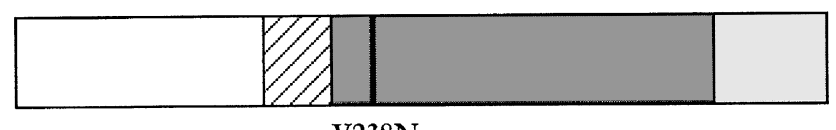

Fas- $\mathrm{IC}_{175-319} \mathrm{~V} 238 \mathrm{~N}$

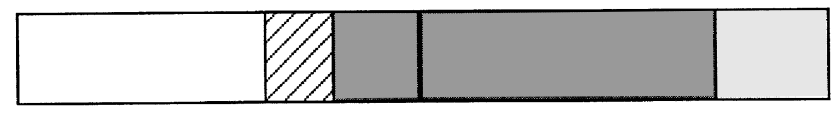

Fas-IC ${ }_{175-319}{ }^{\mathrm{E} 245 \mathrm{~A}}$

E245A

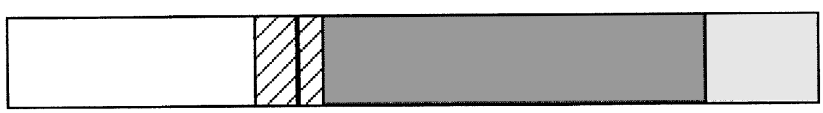

Fas-IC ${ }_{175-319}{ }^{\mathrm{T} 225 \mathrm{P}}$

Figure 1 Diagram of wild-type and mutated human Fas-IC 
expression specifically resulted in death of the host bacteria.

\section{Fas-IC with point mutation V238N or E245A does not kill host bacteria}

The intracellular region of Fas from $/ \mathrm{prg}^{\mathrm{cg}}$ mice harbors a single amino acid substitution, valine to asparagine, at residue 225

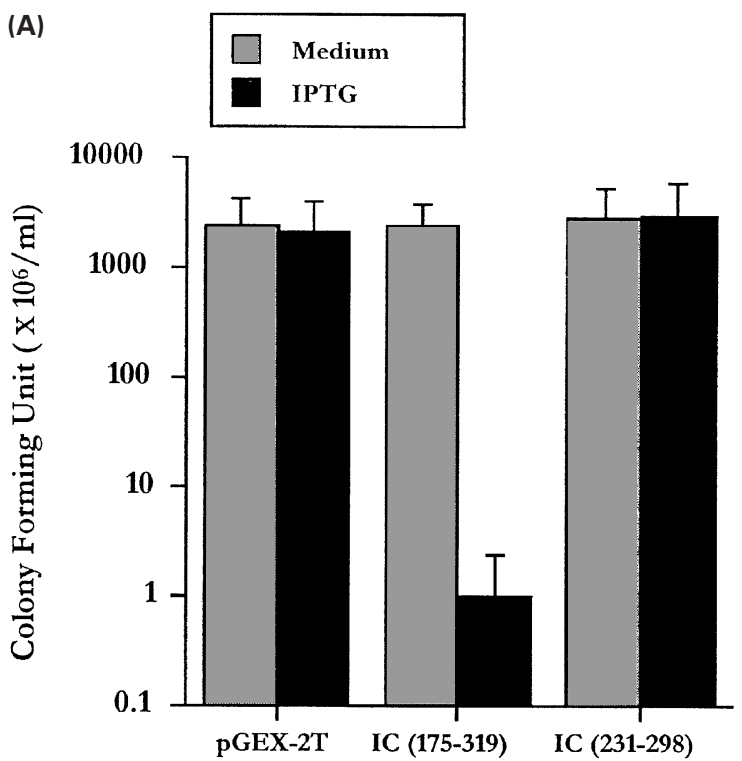

(B)

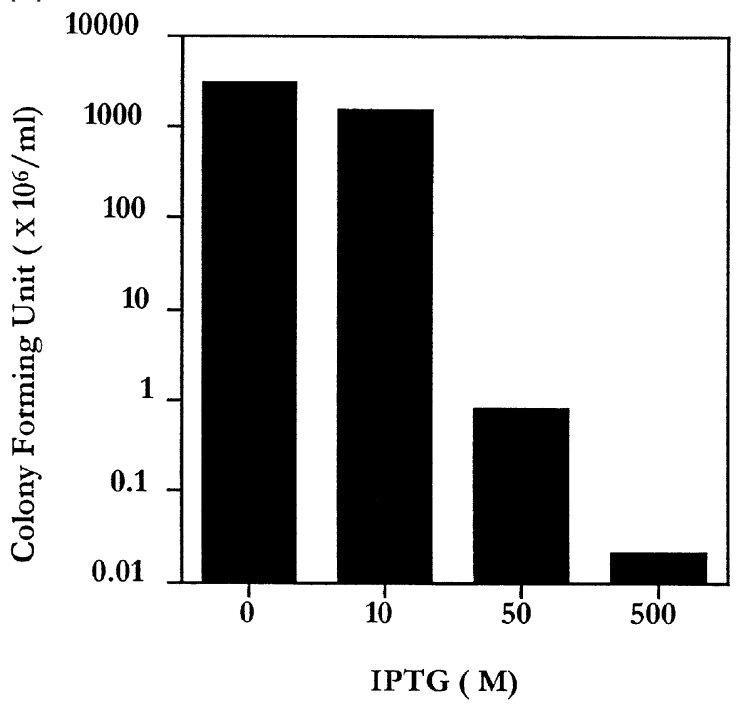

Figure 2 IPTG induces death of bacteria transformed with $\mathrm{PGEX}-\mathrm{IC}_{175-319}$. (A) Numbers of viable bacteria transformed with pGEX-2T, pGEX-IC $175-319$, or pGEX-IC1 $1_{231-298}$ were determined after incubation for $30 \mathrm{~min}$ in the absence or presence of $100 \mu \mathrm{M}$ IPTG. The data represent the mean \pm S.E.M. of five independent experiments. (B) Culture of bacteria transformed with pGEX-IC ${ }_{175-319}$ was divided into several tubes and treated with $0,10,50$ and $500 \mu \mathrm{M}$ IPTG for $30 \mathrm{~min}$. Numbers of viable cells were calculated from the number of colonies on each plate
(V225N). ${ }^{6}$ Ligation of this Fas variant cannot transduce apoptotic signals, resulting in the accumulation of aberrant $\mathrm{T}$ cells in $l p r^{\mathrm{gg}}$ mice. Human Fas with the corresponding mutation, $\mathrm{V} 238 \mathrm{~N}$, is also unable to deliver apoptotic signals when expressed in mouse or human cells. ${ }^{9}$ To determine whether the ability of Fas-IC to kill bacteria is related to induction of apoptosis by Fas in mammalian cells, bacteria were transformed with pGEX-2T, pGEX-IC $175-319$, or pGEX$I_{175-319} V 238 \mathrm{~N}$. The growth curves of bacteria transformed with pGEX-2T were similar in the presence or absence of IPTG, while bacteria transformed with pGEX-IC 175-319 $_{17}$ were killed by induction with IPTG (Figure 4A and B). In contrast to

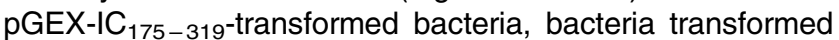
with pGEX-IC $175-319$ V238N grew vigorously after IPTG treatment (Figure 4C).

Induction of apoptosis by ligation of Fas with anti-Fas antibody or Fas ligand requires aggregation of Fas and its association with FADD. ${ }^{15}$ In vitro analysis has demonstrated that human Fas-IC containing the V238N mutation can not self-associate and bind FADD. ${ }^{29,30}$ To determine if self-association, association with a FADD-like molecule, or both is required for Fas-IC to kill bacteria, use was made of Fas-IC containing the substitution E245A, which does not readily self-associate but still can interact with FADD. ${ }^{29}$ As shown in Figure 4D, the growth of $\mathrm{DH} 5 \alpha$ transformed with pGEX-IC $175-319$ E245A was not significantly affected by treatment with IPTG. Together with the data obtained with the V238N mutation, these results indicate that the ability to self-associate is required for Fas-IC to kill bacteria, whereas association with a putative FADD-like molecule alone is not sufficient to lead to bacterial death.

\section{A 20-amino acid region of the intracellular portion of Fas is required for Fas-induced bacterial death}

To determine what region(s) of intracellular Fas contribute to bacterial death, cDNAs encoding truncated forms of Fas-IC were cloned into pGEX-2T. Expression of Fas-IC ${ }_{175-298}$ resulted in death of host bacteria, although about tenfold less efficiently than full length Fas- $\mathrm{IC}_{175-319}$ (note a decrease of approximately 100 -fold in cell number compared to the approximately 1000 -fold decrease caused by Fas-IC $\mathrm{C}_{175-319}$ ) (Figure 5). Interestingly, Fas- $\mathrm{IC}_{175-230}$ killed bacteria as efficiently as $I_{175-298}$, indicating amino acids $230-298$ (the classic death domain) are not essential for Fas-ICmediated toxicity. However, further deletion of 20 amino acids from the $\mathrm{COOH}$-terminus of $\mathrm{IC}_{175-230}$ resulted in high levels of expression of Fas-IC $175-210$ in bacteria treated with IPTG (data not shown) but complete loss of the ability to kill bacteria (Figure 5). Therefore, amino acids 210-230 are required for Fas-IC-induced death of bacteria. These residues are, however, not sufficient, because expression of $\mathrm{GST}_{-} \mathrm{IC}_{210-}$ 230 or even GST-IC $210-319$ did not result in loss of bacterial viability (data not shown).

A single amino acid substitution, T225P, in this required 20-amino acid region of Fas has been shown to prevent Fas from signaling for apoptosis in human cells. ${ }^{31}$ Therefore, the intracellular portion of this mutated Fas was cloned into pGEX-2T and used to transform DH5 $\alpha$. The number of viable bacteria containing pGEX-IC $175-319$ T225P 
IPTG Rhodamine 123
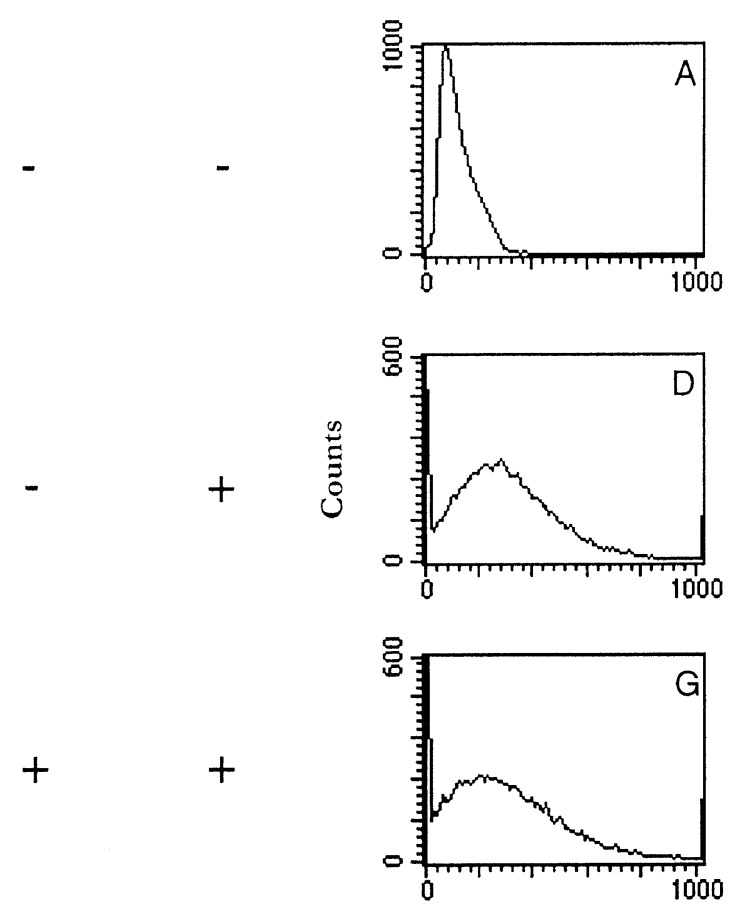

pGEX-IC $175-319$
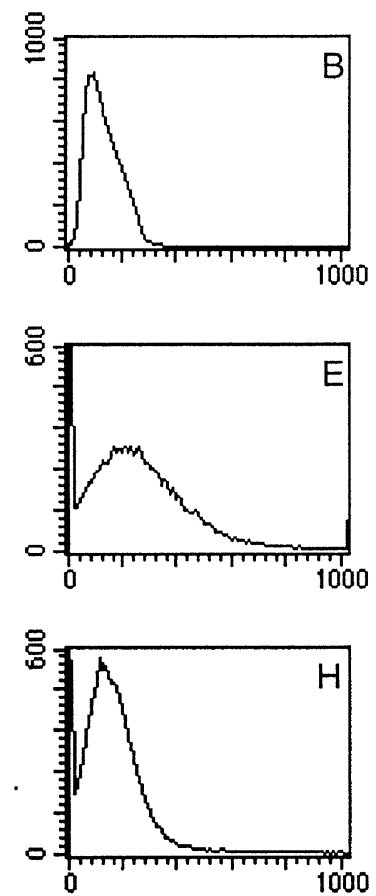

pGEX-IC $231-298$
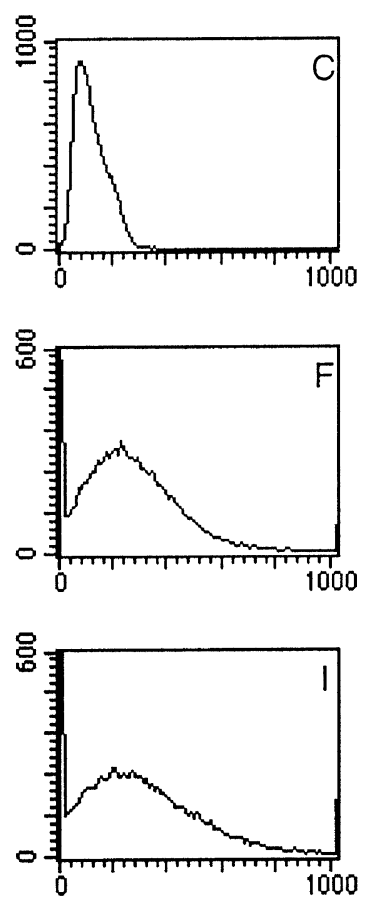

Rhodamine 123 fluorescence

was only slightly affected when treated with IPTG (Figure $6 \mathrm{~A})$. This is not due to lack of expression of fusion protein because GST-IC $175-319$ T225P was induced well by IPTG (Figure 6B). Consistent with this, bacteria containing pGEX$\mathrm{IC}_{175-231}$ with the T225P mutation were also not killed by incubation with IPTG (data not shown). Therefore, the ability of Fas-IC to kill bacteria is closely related to its ability to mediate apoptosis in eukaryotic cells.

\section{Discussion}

Apoptosis, or programmed cell death, is an important mechanism for multicellular organisms to remove unwanted or dangerous cells. ${ }^{32}$ Over the last few years it has been realized that eukaryotic unicellular organisms can also undergo programmed cell death that is similar if not identical to apoptosis. ${ }^{33}$ Even more striking, primitive forms of programmed cell death have been found in prokaryotes. For example, some bacteria carry plasmids that encode stable 'toxin' and labile 'antidote' pairs, such as a restriction enzyme and its cognate DNA methylase. ${ }^{34,35}$ When the plasmid is lost, labile antidotes decrease more rapidly than toxins and the plasmid-free bacteria die. Examples of lethal/protective gene pair systems that ensure the retention of the plasmid on which they reside ('selfish genes') in which the antidote is a protein (rather than antisense RNA) have been termed 'proteic killer gene systems'. ${ }^{36}$ Endogenous suicide pathways can also be triggered by some bacteriophages, affording a protective mechanism to limit the spread of infection. ${ }^{37}$ Bacteria can also commit suicide in response to environmental stress. One such example is bacteria carrying a plasmid encoding colicin that synthesize this toxin in response to DNA damage and die, ${ }^{25}$ reminiscent of mammalian cells that respond to DNAdamaging agents by producing p53 and undergoing apoptosis. ${ }^{38,39}$ Bacterial death in response to environmental stresses (nutrient deprivation, $\mathrm{pH}$ changes, heat shock, etc.) has some similarities to apoptosis (for example, cell shrinkage and protein and RNA degradation), leading to the suggestion that this form of death be termed 'proapoptosis'. ${ }^{0}$ Programmed cell death of unicellular organisms is considered 'altruistic' in that it benefits neighboring cells and maintains the genetic stability of the population. These observations have raised the question of whether these cells have similar cell death machinery and utilize similar 'suicide' mechanisms as cells from multicellular organisms.

Caspases, cysteine proteases that cleave substrates at aspartate residues, are mediators of Fas-mediated apoptosis in eukaryotic cells. ${ }^{13,14}$ We used a panel of fluorogenic substrates that are preferentially cleaved by caspases -2 , $-3,-6,-8$ and -9 , to ask if any caspase-like activity was induced in dying bacteria. None of these substrates was cleaved when added to lysates of pGEX-IC $175-319^{-}$ transformed bacteria made before or after induction with IPTG (data not shown). Consistent with this, we found that the caspase-specific inhibitors z-VAD-FMK, YVAD-FMK, and Ac-DEVD-CHO, and a more general cysteine protease 

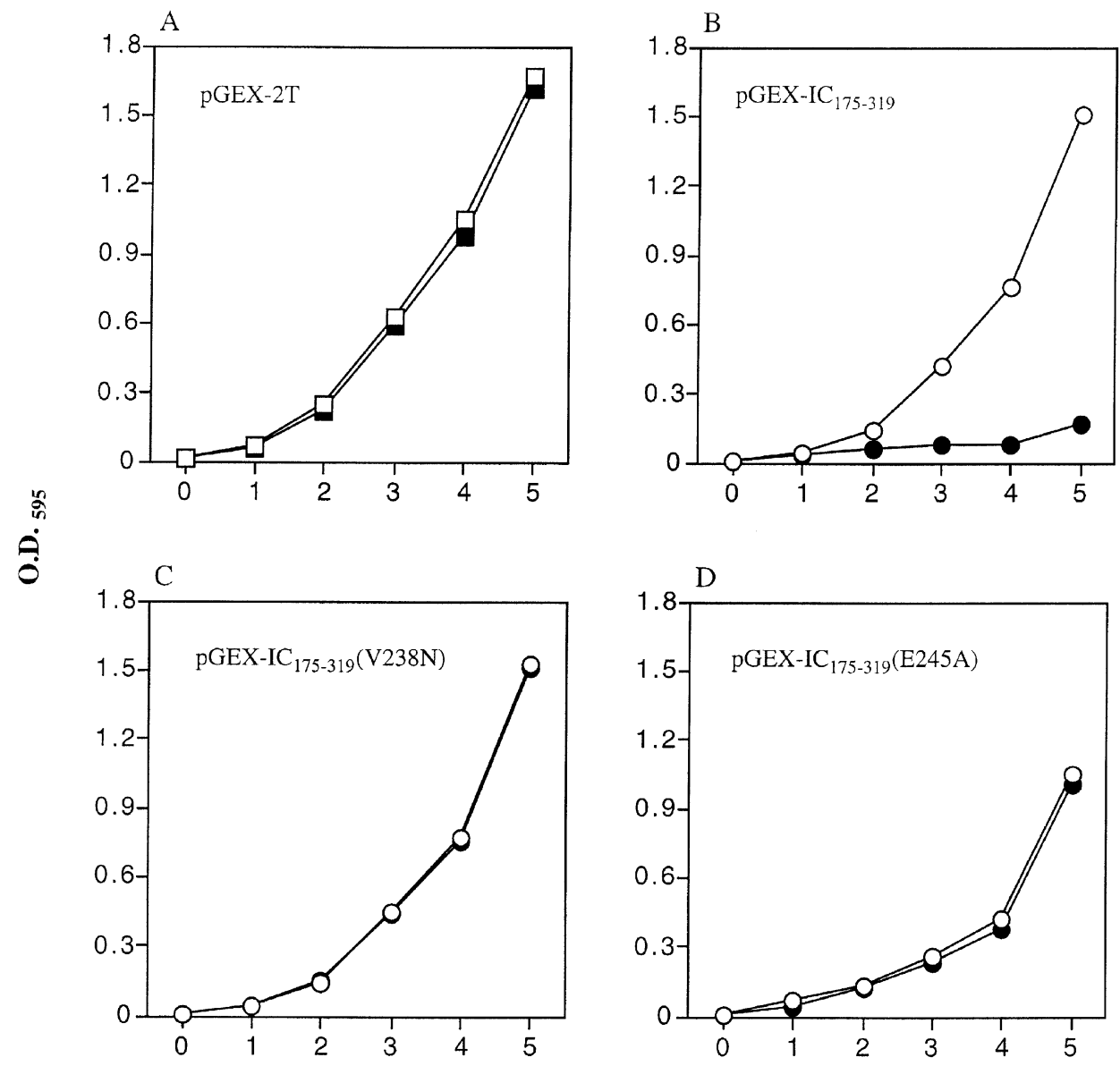

Time (h)

Figure 4 Fas-IC with the single amino acid substitution V238N or E245A does not kill bacteria. Single colonies of bacteria transformed with pGEX-2T, pGEX-

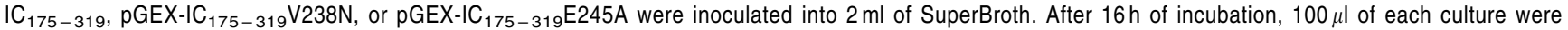
transferred into $10 \mathrm{ml}$ of fresh medium with or without $100 \mathrm{mM}$ IPTG. Absorption at $595 \mathrm{nM}$ was determined at the indicated times

inhibitor Boc-D-FMK, did not prevent Fas-IC-induced bacterial death (data not shown). Furthermore, co-expression of cowpox virus protein CrmA and baculovirus protein p35, both of which have been shown inhibit caspase activity and block Fas-mediated apoptosis, ${ }^{13,41}$ did not rescue bacteria from Fas-IC-induced death (data not shown). These results strongly support the notion that caspase-like enzymes are not involved in Fas-induced bacterial cell death. It is noteworthy in this regard that no molecules homologous to pro-apoptotic or anti-apoptotic molecules such as ced-3, ced-4, ced-9, caspases, or Fas have been identified in the genomes of $S$. cerevesiae and E. coli. Furthermore, caspase-independent Fas-mediated death of mammalian cells has also been observed. ${ }^{42-44}$ Interestingly, in yeast expression of the mammalian proapoptotic molecules Bax and Bak resulted in death while expression of mutants of Bax and Bak that cannot kill mammalian cells did not cause yeast cell death. ${ }^{45-47}$ Furthermore, coexpression of Bcl-2 blocked the cytotoxicity

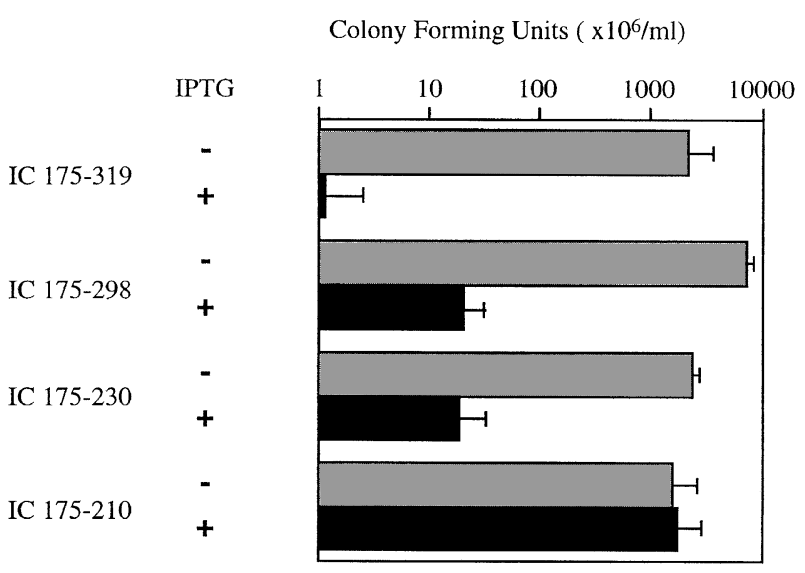

Figure 5 Toxicity of $\mathrm{COOH}$-terminal truncated Fas-ICs in bacteria. Wild-type and $\mathrm{COOH}$-terminal-truncated Fas-IC cDNAs were cloned into pGEX-2T and transformed into $\mathrm{DH} 5 \alpha$. The numbers of viable cells in the cultures were determined as described in Material and Methods 


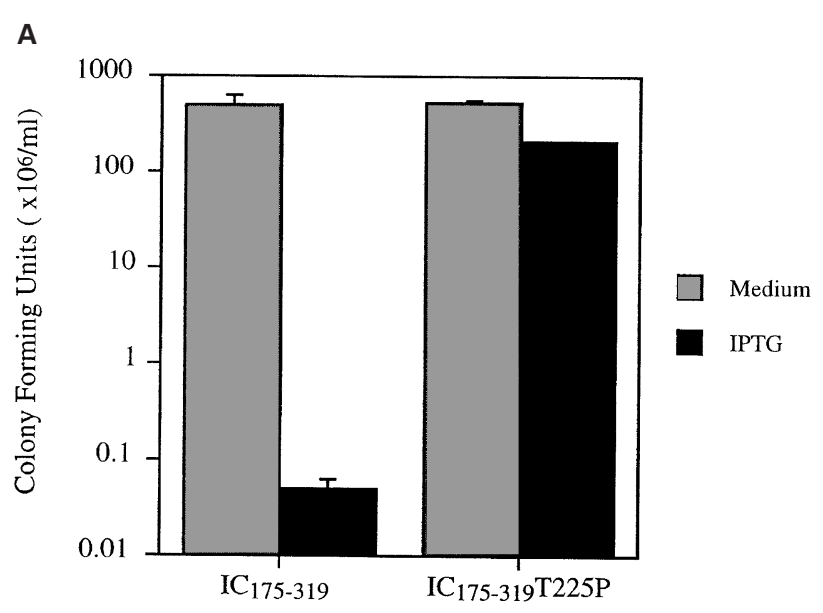

B
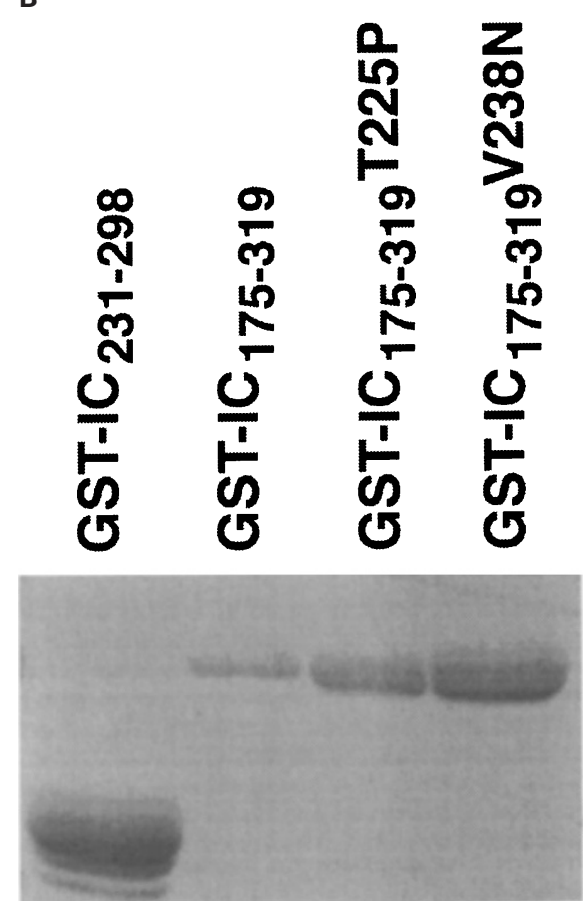

Figure 6 T225P mutation abolishes the ability of Fas-IC to kill host bacteria. (A) Numbers of viable bacteria transformed with pGEX-IC $175-319$ or pGEX$\mathrm{IC}_{175-319}$ T225P after treatment with $100 \mu \mathrm{M}$ IPTG. (B) Bacteria transformed with pGEX-IC $231-298$, pGEX-IC $175-319$, pGEX-IC P $_{175-319}$ T225P, and pGEX$I C_{175-319} \mathrm{~V} 238 \mathrm{~N}$ were grown in medium until O.D.595 reached 0.4. After induction with $100 \mu \mathrm{M} \mathrm{IPTG}$ for $30 \mathrm{~min}$, pGEX-IC $231-298$, GST-IC ${ }_{175-319}$, GST-IC $175-319$ T225P, and GST-IC $175-319 \mathrm{~V} 235 \mathrm{~N}$ were purified by binding to glutathione Sepharose 4B and examined by SDS-PAGE and Coomassie Blue staining

of Bax and Bak in yeast, indicating that the ability of Bax and Bak to kill yeast cells is related to their ability to induce apoptosis in mammalian cells. Similar results were obtained when pro-apoptotic ced-4 and anti-apoptotic ced-9 were expressed in $S$. pombe. ${ }^{48}$ Intriguingly, the effects of Bax and ced-4 on yeast cells are also somewhat different from their action in mammalian and $C$. elegans cells. For example, ced-4 exerts its pro-apoptotic action in $C$. elegans through activation of ced-3, whereas the cytotoxicity of ced-4 in yeast cannot be blocked by coexpression of p35, a potent inhibitor of ced-3. ${ }^{48}$ This is similar to our observation Fas-IC-induced bacterial death shares some but not all features with that induced in mammalian cells. In addition, we have found that induction of Bax also results in death of host bacteria, which can not be inhibited by coexpression of p35 (our unpublished data). Given the complexity of eukaryotic cells, expression of pro-cell death molecules in bacteria could be a very useful way to identify and characterize critical cellular components.

An important issue to consider with regard to the observation that expression of intracellular Fas kills bacteria is whether death is induced by a Fas-specific mechanism. Bacteria are commonly used for the production of heterologous proteins, and when proteins are greatly overexpressed bacteria may cease growth and die. ${ }^{49}$ This is thought to be due to a starvation response that leads to, among other things, destruction of ribosomes. ${ }^{50}$ This does not appear to be the mechanism responsible for Fas-IC $175-319$-induced bacteria death for several reasons. First, the expression level of Fas- $\mathrm{IC}_{175-}$ 319 is low compared to that of Fas- $I_{230-298}$, Fas- $I_{175-}$ 210, Fas $-I_{175-319} V 238 N$, none of which affected the growth of $E$. coli. Second, the effect of expressing Fas$\mathrm{IC}_{175-391}$ on host bacteria was evident by direct staining or plating after treatment with IPTG for only $30 \mathrm{~min}$, whereas growth inhibition caused by enforced expression of exogenous protein takes hours. Third, the ability of Fas$\mathrm{IC}_{175-319}$ to kill bacteria was associated with a 20-amino acid region and correlates well with its ability to induce apoptosis in mammalian cells, indicating that bacterial death is due to the specific cytotoxicity of Fas-IC. In fact, it has been known for more than a decade that expression of certain eukaryotic proteins in $E$. coli can result in death despite low protein yield. ${ }^{51-53}$ Much like the early days in the study of apoptosis, however, the mechanisms underlying this type of death have received little attention and are largely unknown. Understanding the means by which Fas-IC kills bacteria may provide insights into the more general mechanisms of bacterial death.

An interesting issue is whether killing of bacteria by FasIC requires interaction with a FADD-like molecule. Fas-IC containing the V238N mutation is unable to bind FADD in eukaryotic cells, ${ }^{30}$ and in fact was unable to kill bacteria. However, although it is able to bind FADD in mammalian cells, Fas- $\mathrm{IC}_{175-319}$ with a single amino acid substitution E245A did not kill host bacteria. Moreover, expression of Fas- $-C_{175-230}$, which cannot bind to FADD, ${ }^{18}$ does cause the death of bacteria. Together, these results suggest that association with FADD-like molecule is not required for Fas-IC to induce death of bacteria. It is interesting to note that although V238 and E245 are not located in the minimal required region $\left(\mathrm{IC}_{175-230}\right)$ required for killing activity, FasIC with single amino acid substitutions at these sites are inactive with regard to bacterial death. This is likely because these mutations disrupt the structure of Fas-IC, as suggested NMR data that they cannot efficiently selfassociate and the V238N mutant had many ${ }^{15} \mathrm{~N} /{ }^{1} \mathrm{H}$ amide chemical shifts compared with wild-type Fas-IC. ${ }^{29}$ The 
NMR studies indicated that Fas-IC has six $\alpha$-helices, and that amino acids 210-230, which are required for the majority of the bactericidal activity, includes the $\mathrm{NH}_{2}-$ proximal helices $\alpha 1$ and $\alpha 2 .^{29}$ It is conceivable that this region binds evolutionarily-conserved components of the Fas-mediated apoptosis signaling pathway. It is hoped that exploration of the molecular requirements for Fas-induced killing of bacteria may shed light on conserved mechanisms for the induction of death in eukaryotic cells.

\section{Materials and Methods}

\section{Bacteria strains, cells, medium, and reagents}

$\mathrm{DH} 5 \alpha$ E. coli were purchased from Gibco- BRL (Gaithersburg, MD, USA) and cultured in Super Broth medium. Isopropylthiogalactoside (IPTG) and Rhodamine 123 were purchased from Sigma (St. Louis, MO, USA). Jurkat cells were cultured in RPMI 1640 (Biofluids Inc., Rockville, MD, USA) supplemented with $10 \%$ FCS, $100 \mathrm{U} / \mathrm{ml}$ penicillin, $150 \mu \mathrm{g} / \mathrm{ml}$ gentamicin, and $5 \times 10^{-5} \mathrm{M}$ 2-mercaptoethanol. The antihuman Fas antibody $\mathrm{CH}-11$ was purchased from Kamiya (Seattle, WA, USA).

\section{Plasmids constructs}

The prokaryotic expression vector pGEX-2T was obtained from Pharmacia (Uppsala, Sweden). Human Fas cDNA was kindly provided by Drs. John Mountz and Jianhua Cheng (University of Alabama at Birmingham Station, Birmingham, AL, USA). CDNAs of intracellular portion of Fas $\left(\mathrm{IC}_{175-319}\right)$ and death domain $\left(\mathrm{IC}_{231-298}\right)$ were generated by PCR using primers (1) 5'-CGGGATCCA AGAGAAAGGAAGTACAGAA-3' and (2) 5'-GGAATTCCTAGACCAAGCTTTGGATTT-3', and (3) 5'-CGGGATCCGGCTTTGTTCG AAAGAATGG-3' and (4) 5'-GGAATTCCTAGATG ATAGTCTGAATTTTCT-3' respectively. They were cloned into BamHI and EcoRI double-digested pGEX-2T and the sequences of the constructs were confirmed by DNA sequencing. Similarly, cDNAs of $\mathrm{IC}_{175-298}$, $I C_{175-230}$, and $I C_{175-210}$ were made using primers (1) and primer (4), (1) and (5) 5'-GGAATTCTATTTAACTTGACTTAGTGTCAT-3', and (1) and (6) 5'-GGAATTCCT AAGATAAATTTATTGCCA-3' respectively. Human Fas cDNA with the T225P substitution was kindly provided by Dr. Charles Zacharchuk (National Cancer Institute, NIH, Bethesda, MD, USA). Fas-IC with the V238N and E245A single amino acid substitutions were generated using the QuikChange Site-Directed Mutagenesis Kit (Stratagene, La Jolla, CA, USA) and confirmed by DNA sequencing.

\section{Protein expression and detection}

Intracellular portions of Fas were expressed as GST-Fas-IC fusion proteins following induction with $100 \mu \mathrm{M}$ of IPTG. They were purified with glutathione Sepharose $4 \mathrm{~B}$ according to the manufacturer's protocol (Pharmacia, Uppsala, Sweden). After separation on $12 \%$ SDS-PAGE, proteins were visualized by Coomassie Brilliant Blue $\mathrm{R}-250$ staining.

\section{Viable bacteria enumeration}

A single bacterial colony transformed with the indicated plasmid was inoculated in medium and incubated for approximately $4 \mathrm{~h}$. After further incubation in the presence or absence of IPTG for $30 \mathrm{~min}$, a small amount of the culture was diluted and spread over the surface of an LB plate containing $100 \mathrm{mg} / \mathrm{ml}$ of ampicillin. After overnight incubation, the number of viable cells was determined from the number of colonies on the plates.

\section{Assessment of bacterial viability by flow cytometry}

Viability of bacteria was assessed by staining with the vital fluorescent dye rhodamine 123 as described. ${ }^{27}$ Briefly, a single colony of $\mathrm{DH} 5 \alpha$ cells transformed with the indicated plasmid was grown in Super Broth medium for approximately $4 \mathrm{~h}$. After further incubation in the absence or presence of IPTG for $30 \mathrm{~min}$, bacteria were harvested and washed three times with $50 \mathrm{mM}$ Tris buffer $(\mathrm{pH} \mathrm{7.5)}$ containing $5 \mathrm{mM}$ EDTA. The pellets were resuspended in medium containing $100 \mathrm{ng} / \mathrm{ml}$ of rhodamine 123 and incubated at room temperature for $10 \mathrm{~min}$. Flow cytometric analysis was carried out with a FACScan (Becton Dickinson, San Jose, CA, USA).

\section{References}

1. Itoh N, Yonehara S, Ishii A, Yonehara M, Mizushima S-I, Sameshima M, Hase A, Seto Y and Nagata S(1991) The polypeptide encoded by the CDNA for human cell surface antigen Fas can mediate apoptosis. Cell 66: 233-243

2. Oehm A, Behrmann I, Falk W, Pawlita M, Maier G, Klas C, Li-Weber M, Richards S, Dhein J, Trauth BC, Ponstingl $\mathrm{H}$ and Krammer PH (1992) Purification and molecular cloning of the APO-1 cell surface antigen, a member of the tumor necrosis factor/nerve growth factor receptor superfamily. Sequence identity with the Fas antigen. J. Biol. Chem. 267: 10709-10715

3. Trauth BC, Klas C, Peters AMJ, Matzku S, Möller P, Falk W, Debatin K-M and Krammer PH (1989) Monoclonal antibody-mediated tumor regression by induction of apoptosis. Science 245: 301-304

4. Yonehara S, Ishii A and Yonehara M (1989) A cell-killing monoclonal antibody (anti-Fas) to a cell surface antigen co-downregulated with the receptor of tumor necrosis factor. J. Exp. Med. 169: 1747-1756

5. Suda T, Takahashi T, Golstein P and Nagata S (1993) Molecular cloning and expression of the Fas ligand, a novel member of the tumor necrosis factor family. Cell 75: $1169-1178$

6. Watanabe-Fukunaga R, Brannan $\mathrm{Cl}$, Copeland NG, Jenkins NA and Nagata S (1992) Lymphoproliferation disorder in mice explained by defects in Fas antigen that mediates apoptosis. Nature 356: 314-317

7. Henkart PA (1994) Lymphocyte-mediated cytotoxicity: two pathways and multiple effector molecules. Immunity 1: 343-346

8. Green DR and Ware CF (1997) Fas-ligand: privilege and peril. Proc. Natl. Acad. Sci. USA. 94: $5986-5990$

9. Itoh $\mathrm{N}$ and Nagata S (1993) A novel protein domain required for apoptosis. Mutational analysis of human Fas antigen. J. Biol. Chem. 268: 10932-10937

10. Tartaglia LA, Ayres TM, Wong GH and Goeddel DV (1993) A novel domain within the 55 kd TNF receptor signals cell death. Cell 74: 845-853

11. Boldin MP, Goncharov TM, Goltsev YV and Wallach D (1996) Involvement of $\mathrm{MACH}$, a novel MORT1/FADD-interacting protease, in Fas/APO-1- and TNF receptor-induced cell death. Cell 85: 803-815

12. Muzio M, Chinnaiyan AM, Kischkel FC, O'Rourke K, Shevchenko A, Ni NJ, Scaffidi C, Bretz JD, Zhang M, Gentz R, Mann M, Krammer PH, Peter ME and Dixit VM (1996) FLICE, a novel FADD-homologous ICE/CED-3-like protease, is recruited to the CD95 Fas/APO-1 death-inducing signaling complex. Cell 85 : $817-827$

13. Enari M, Hug H and Nagata S (1995) Involvement of an ICE-like protease in Fasmediated apoptosis. Nature 375: 78-81

14. Los M, Van de Craen M, Penning LC, Schenk K, Westendorp M, Baeuerle PA, DrögeW, KrammerPH, Fiers Wand Schulze-Osthoff K(1995) Requirement of an ICE/CED-3 protease for Fas/APO-1-mediated apoptosis. Nature 375: $81-83$

15. Nagata S (1997) Apoptosis by death factor. Cell 88: 355-365

16. Memon SA, Hou J, Moreno MB and Zacharchuk CM (1998)Apoptosis induced by a chimeric Fas/FLICE receptor: lack of requirement for Fas- or FADD-binding proteins. J. Immunol. 160: 2046-2049 
17. Yang X, Chang HY and Baltimore D (1998) Autoproteolytic activation of procaspases by oligomerization. Mol. Cell. 1: 319-325

18. Chinnaiyan AM, O'Rourke K, Tewari M and Dixit VM (1995) FADD, a novel death domain-containing protein, interacts with the death domain of Fas and initiates apoptosis. Cell 81: 505-512

19. Ivanov VN, Lee RK, Podack ER and Malek TR (1997) Regulation of Fasdependent activation-induced T cell apoptosis by CAMP signaling: a potential role for transcription factor NF- $k$ B. Oncogene 14: 2455-2464

20. Su X, Zhou T, Wang Z, Yang P, Jope RS and Mountz JD (1995) Defective expression of hematopoietic cell protein tyrosine phosphatase (HCP) in lymphoid cells blocks Fas-mediated apoptosis. Immunity 2: 353-362

21. Stanger BZ, Leder P, Lee T-H, Kim E and Seed B (1995) RIP: a novel protein containing a death domain that interacts with Fas/APO-1 (CD95) in yeast and causes cell death. Cell 81: 513-523

22. ChuJL, Ramos P, Rosendorff A, Nikolic-Zugic J, LacyE, Matsuzawa A and Elkon KB (1995) Massive upregulation of the Fas ligand in /prand gld mice: implications for Fas regulation and the graft-versus-host disease-like wasting syndrome. J. Exp. Med. 181: 393-398

23. Sato T, Irie S, Kitada S and Reed JC (1995) FAP-1: a protein tyrosine phosphatase that associates with Fas. Science 268: 411-415

24. Yang X, Khosravi-Far R, Chang HY and Baltimore D (1997) Daxx, a novel Fasbinding protein that activates JNK and apoptosis. Cell 89: 1067-1076

25. Yarmolinsky MB (1995) Programmed cell death in bacterial populations. Science 267: 836-837

26. Mason D, Allman R and Lloyd D (1993) Uses of membrane potential sensitive dyes with bacteria. In: Lloyd D, ed. Flow cytometry in Microbiology. New York: Springer-Verlag; $67-81$

27. Kaprelyants AS and Kell DB (1992) Rapid assessment of bacteria viability and vitality by rhodamine 123 and flow cytometry. J. Appl. Bacteriol. 72: 410-422

28. Johnson LV, Walsh ML and Chen LB (1980) Localization of mitochondria in living cells with rhodamine 123. Proc. Natl. Acad. Sci. USA. 77: 990-994

29. Huang B, Eberstadt M, Olejniczak ET, Meadows RP and Fesik SW (1996) NMR structure and mutagenesis of the Fas (APO-1/CD95) death domain. Nature 384: $638-641$

30. Eberstadt M, Huang B, Olejniczak ET and Fesik SW (1997) The lymphoproliferation mutation in Fas locally unfolds the Fas death domain. Nat. Struct. Biol. 4: 983-985

31. Fisher GH, Rosenberg FJ, Straus SE, Dale JK, Middleton LA, Lin AY, Strober W Lenardo MJ and Puck JM (1995) Dominant interfering Fas gene mutations impair apoptosis in a human autoimmune lymphoproliferative syndrome. Cell 81:935946

32. Raff MC (1992) Social controls on cell survival and cell death. Nature 356: $397-$ 400

33. Ameisen JC (1996) The origin of programmed cell death. Science 272: 1278 1279

34. Naito T, Kusano K and Kobayashi I (1995) Selfish behavior of restrictionmodification systems. Science 267: 897-899

35. Jensen RB and Gerdes K (1995) Programmed cell death in bacteria: proteic plasmid stabilization systems. Mol. Microbiol. 17: 205-210

36. Fraser $A$ and James $C$ (1998) Fermenting debate: do yeast undergo apoptosis? Trends Cell Biol. 8: 219-221
37. Djordjevic GM, O'Sullivan DJ, Walker SA, Conkling MA and Klaenhammer TR (1997) A triggered-suicide system designed as a defense against bacteriophages. J. Bacteriol. 179: 6741-6748

38. Lowe SW, Schmitt EM, Smith SW, Osborne BA and Jacks T (1993) p53 is required for radiation-induced apoptosis in mouse thymocytes. Nature 362 : 847-849

39. Clarke AR, Purdie CA, Harrison DJ, Morris RG, Bird CC, Hooper ML and Wyllie AH (1993) Thymocyte apoptosis induced by p53-dependent and independent pathways. Nature $362: 849-852$

40. Hochman A (1997) Programmed cell death in prokaryotes. Crit. Rev. Microbiol. 23: $207-214$

41. Enari M, Talanian RV, Wong WW and Nagata S (1996) Sequential activation of ICE-like and CPP32-like proteases during Fas-mediated apoptosis. Nature 380: $723-726$

42. Toyoshima F, Moriguchi T and Nishida E (1997) Fas induces cytoplasmic apoptotic responses and activation of the MKK7-JNK/SAPK and MKK6-p38 pathways independent of CPP32-like proteases. J. Cell Biol. 139: 1005-1015

43. Kawahara A, Ohsawa Y, Matsumura H, Uchiyama $Y$ and Nagata S (1998) Caspase-independent cell killing by Fas-associated protein with death domain. J. Cell. Biol. 143: 1353-1360

44. Vercammen D, Brouckaert G, Denecker G, Van de Craen M, Declerq W, Fiers W and Vandenabeele $P(1998)$ Dual signaling of the Fas receptor: initiation of both apoptotic and necrotic cell death pathways. J. Exp. Med. 188: 919-930

45. Zha H, Fisk HA, Yaffe MP, Mahajan N, Herman B and Reed JC (1996) Structurefunction comparisons of the proapoptotic protein Bax in yeast and mammalian cells. Mol. Cell. Biol. 16: 6494-6508

46. Greenhalf W, Stephan C and Chaudhuri B (1996) Role of mitochondria and Cterminal membrane anchor of $\mathrm{Bcl}-2$ in $\mathrm{Bax}$ induced growth arrest and mortality in Saccharomyces cerevisiae. FEBS Lett. 380: 169-175

47. TaoW, KurschnerC and Morgan JI (1997) Modulation of cell death in yeast by the Bcl-2 family of proteins. J. Biol. Chem. 272: 15547-15552

48. James C, Gschmeissner S, Fraser A and Evan GI (1997) CED-4 induces chromatin condensation in Schizosaccharomyces pombe and is inhibited by direct physical association with CED-9. Curr. Biol. 7: 246-252

49. Dong H, Nilsson Land Kurland CG (1995) Gratuitous overexpression of genes in Escherichia colileads to growth inhibition and ribosome destruction. J. Bacteriol. 177: $1497-1504$

50. Kurland CG and Dong $H$ (1996) Bacterial growth inhibition by overproduction of protein. Mol. Microbiol. 21:1-4

51. Brosius J (1984) Toxicity of an overproduced foreign gene product in Escherichia coli and its use in plasmid vectors for the selection of transcription terminators. Gene 27: 161-172

52. Sisk WP, Bradley JD, Kingsley D and Patterson TA (1992) Deletion of hydrophobic domains of viral glycoproteins increases the level of their production in Escherichia coli. Gene 112: 157-162

53. Markiewicz E, Wilczynski G, Filipski J and Szopa J (1997) Modification of the apoptotic-like effects of MBP protein overexpression in E. coliby fusion with 14-33 derived polypeptides. Cell Death Differ. 4: 272-275 